\title{
Relationship between mitral leaflets angles, left ventricular geometry and mitral deformation indices in patients with ischemic mitral regurgitation: imaging by echocardiography and cardiac magnetic resonance
}

\author{
Agata Leśniak-Sobelga $\cdot$ Ewa Wicher-Muniak $\cdot$ Magdalena Kostkiewicz • \\ Maria Olszowska • Piotr Musiałek • Piotr Klimeczek • Paweł Banyś • \\ Mieczysław Pasowicz $\cdot$ Wiesława Tracz $\cdot$ Piotr Podolec
}

Received: 7 June 2010/ Accepted: 22 December 2010/Published online: 7 January 2011

(C) The Author(s) 2010. This article is published with open access at Springerlink.com

\begin{abstract}
Chronic ischemic mitral regurgitation (IMR) is associated with a markedly worse prognosis after myocardial infarction (MI).The study aimed to evaluate the relationship between anterior and posterior mitral leaflet angle (MLA) values, left ventricle remodeling and severity of ischaemic mitral regurgitation (IMR). Methods: Forty-two patients (age $63.5 \pm 9.7$ years, 36 men) with chronic IMR (regurgitant volume, RV > $20 \mathrm{ml}$; $>6$ months after MI) underwent transthoracic echocardiography (TTE) and cardiovascular magnetic resonance (CMR) imaging. Anterior and posterior MLA, determined by echocardiography, were correlated with indices of LV remodeling, mitral apparatus deformation and IMR severity by CMR. The anterior and posterior MLA was $25.41 \pm 4.28$ and $38.37 \pm 8.89^{\circ}$ (mean \pm SD). In 5 patients $\left(11.9 \%\right.$ ) the posterior MLA was $\geq 45^{\circ}$. There was a significant correlation between anterior MLA and RV $(r=0.74, P=0.01)$. For patients with $\mathrm{RV}>30 \mathrm{ml}$ this correlation was stronger $(r=0.97$, $P=0.005)$ and, in addition, there was a correlation
\end{abstract}

A. Leśniak-Sobelga $(\bowtie) \cdot$ M. Kostkiewicz ·

M. Olszowska · P. Musiałek · W. Tracz · P. Podolec

Department of Cardiac and Vascular Diseases,

Jagiellonian University School of Medicine, John Paul II

Hospital, Prądnicka 80 Str., 31-202 Kraków, Poland

e-mail: alesniak@szpitaljp2.krakow.pl

E. Wicher-Muniak · P. Klimeczek · P. Banyś ·

M. Pasowicz

Center for Diagnosis, Prevention and Telemedicine,

John Paul II Hospital, Kraków, Poland between the RV and posterior MLA $(r=0.90$, $P=0.037)$, between tenting area and posterior MLA ( $r=0.90, P=0.04)$, and between tenting area and anterior MLA $(r=0.82, P=0.08)$. With regard to $\mathrm{LV}$ remodeling parameters, there was weaker but significant correlation between posterior MLA and LV end-diastolic volume index $(r=0.35, P=0.031), \mathrm{LV}$ end-systolic volume index $(r=0.37, P=0.021)$, stroke volume $(r=0.35, \quad P=0.03), \quad$ sphericity index $(r=0.33$, $P=0.041)$. Anterior MLA correlated with wall motion score index $(r=0.41, P=0.019)$. Besides, there was a correlation between posterior MLA and left atrial volume ( $r=0.41, P=0.012$ ). Measurement of anterior and posterior MLA may play an important role in evaluating patients with IMR.

Keywords Ischaemic mitral regurgitation . Mitral leaflet angles - Cardiac magnetic resonance . Echocardiography

\section{Introduction}

Chronic ischemic mitral regurgitation (IMR) is associated with a markedly worse prognosis after myocardial infarction (MI). IMR is associated with left ventricular (LV, both regional and global) remodeling and mitral valve dysfunction. Mitral regurgitation is more likely to occur after posteroinferior than anterolateral MI $[1,2]$. 
Restrictive mitral valve annuloplasty is currently recommended in surgical treatment of patients with IMR. However, IMR often persists or recurs after this procedure. It has been indicated that the posterior mitral leaflet angle $\geq 45^{\circ}$ may be an accurate predictor of persistent or recurrent mitral regurgitation. Moreover, the posterior mitral leaflet angle $\geq 45^{\circ}$ can be associated with a poor clinical outcome over a 3-year follow up [3].

This study was undertaken to establish the relationship between anterior and posterior mitral leaflet angle values, the LV remodeling and severity of ischaemic mitral regurgitation.

\section{Materials and methods}

Study group

The study included 42 patients ( $36 \mathrm{M}, 6 \mathrm{~F}$; mean age: $63.5 \pm 9.7$ years) with previous ( $>6$ months) MI (see Table 1 for MI localization) with chronic IMR (regurgitant volume, $\mathrm{RV}>20 \mathrm{ml}$ by CMR). Twenty-five patients $(59.5 \%)$ had previous revascularization procedures (PCI-17, $\mathrm{CABG}-7 ; 1$ patient had PCI followed by $\mathrm{CABG}$; the revascularization procedures were performed 7 to 62 months before the study).

The patients with prior MV repair procedures were excluded from the study group.

The demographic data are shown in Table 1.

All subjects underwent transthoracic echocardiography (TTE) and cardiac magnetic resonance (CMR) imaging within the period of $\leq 5$ days. On TTE, 24 patients had asymmetric tethering of mitral valve leaflets and the remaining 18 had symmetric tethering. The exclusion criteria were as follows: prior MV repair procedures, concomitant organic mitral valve disease, significant aortic stenosis and/or aortic regurgitation, hemodynamic instability, unstable angina, cardiac arrhythmias causing precluding ECG-gated CMR acquisition, and conventional contraindications to CMR [4]. Patients after surgical revascularization with the use of vascular clips or stent-assisted coronary angioplasty were not excluded from CMR studies.

The Ethics Committee of our Institution has approved the protocol, and all patients signed a written consent to be part of the study.
Table 1 The demographic data of study group of patients

\begin{tabular}{|c|c|}
\hline Number of patients & 42 \\
\hline Age (years) & $63.5 \pm 9.7$ \\
\hline Male/female & $36 / 6$ \\
\hline Anterior infarction & $14(33.3 \%)$ \\
\hline Inferior infarction & $17(40.5 \%)$ \\
\hline $\begin{array}{l}\text { Other localization of MI (antero-inferior, antero- } \\
\text { lateral, infero-lateral) }\end{array}$ & $11(26.2 \%)$ \\
\hline \multicolumn{2}{|l|}{ Revascularization } \\
\hline CABG & $7(16.7 \%)$ \\
\hline PCI & $17(40.5 \%)$ \\
\hline CABG and PCI & $1(2.3 \%)$ \\
\hline Hypertension & $34(80.9 \%)$ \\
\hline Systolic blood pressure $(\mathrm{mmHg})$ & $128 \pm 15$ \\
\hline Diastolic blood pressure $(\mathrm{mmHg})$ & $78 \pm 8$ \\
\hline Diabetes & $10(23.8 \%)$ \\
\hline BMI & $26 \pm 3.3$ \\
\hline Hyperlipidaemia & $39(92.9 \%)$ \\
\hline Smoking & $31(73.8 \%)$ \\
\hline NYHA class III-IV & $18(28.5 \%)$ \\
\hline CCS III-IV & $11(26.2 \%)$ \\
\hline
\end{tabular}

$B M I$ Body mass index, $C A B G$ Coronary artery by-pass grafting, CCS class Classification of the Canadian Cardiovascular Society, MI Myocardial infarction, NYHA class New York Heart Association class, PCI Percutaneous coronary intervention

\section{TTE}

The patients underwent a complete two-dimensional echocardiographic and Doppler study. Echocardiographic studies were performed using Vivid $7 \mathrm{GE}$ Dimension device with a $2.0-3.7 \mathrm{MHz}$ transducer. Echocardiographic measurements were obtained in compliance with the guidelines of the American Society of Echocardiography [5]. The measurements were averaged over 3 cardiac cycles.

\section{CMR}

CMR examinations was performed using the 6elements body phased-array "sandwich type" coil (1.5 T MR device-Magnetom Sonata Maestro Class, Siemens, Germany). CMR examination included localizers sequences and the sequences to assess of LV function and aortic flow, which are necessary to mitral regurgitant volume evaluation. Images were acquired in standard two-chamber, three-chamber and four-chamber long-axis view. The localizers 
sequences consisted of static sequences on breathhold (TrueFISP) and cine localizers sequences on breath-hold ECG gated (TrueFISP). The short-axis series from LV base to apex of cine MRI loops was also performed for volumetric and function analysis of LV (cine TrueFISP, slice thickness $8 \mathrm{~mm}, \mathrm{FOV} \geq$ $300 \times 300 \mathrm{~mm}^{2}, \mathrm{TR} \geq 25 \mathrm{~ms}, \quad \mathrm{TE} \geq 1 \mathrm{~ms}, \quad 9-13 \mathrm{~s}$ for every slice). Aortic flow was assessed using velocity encoded contrast-phase imaging and segmented cine FLASH-2D (slice thickness $5 \mathrm{~mm}$, FOV $\geq 200$ $\times 250 \mathrm{~mm}^{2}, \quad \mathrm{TR} \geq 28 \mathrm{~ms}, \quad \mathrm{TE} \geq 3.2 \mathrm{~ms}$ ). Both through plane sequences were planned on the level 2-5 $\mathrm{mm}$ above aortic valve plane (isocentric localization). Individual prediction of aortic peak velocity was evaluated every time (about $170-200 \mathrm{~cm} / \mathrm{s}$ ). LV volumetric and function analysis was performed by manual outlining of the endocardial borders at end-diastole and end-systole at all levels with derivation of end-diastolic volume (LVEDV), end-systolic volume (LVESV), stroke volume (SV), ejection fraction (EF) using the commercially available software-Argus Platform, Siemens Medical Systems. Mitral regurgitation volume was measured by subtracting the aortic flow, derived form contrast-phase imaging, from the SV. The mitral deformation indices were obtained using cine threechamber view images [6-8].

Evaluated parameters

Anterior and posterior mitral leaflet angles were determined by TTE and CMR in the 4-chamber view in mid-systole. The AML and PML angles were measured directly between the mitral leaflets and mitral annulus plane [3] as shown in Fig. 1.

CMR was used to evaluate (1) the mitral deformation indices including coaptation height $(\mathrm{CH})$, tenting area (TA), mitral annulus diameters in systole and diastole (MADs and MADd), mitral annular area in systole and diastole (MAAs and MAAd), left atrial volume (LAV) and (2) left ventricular remodeling parameters including left ventricular end-systolic diameter (LVESD), left ventricular end-diastolic diameter (LVEDD), left ventricular end-systolic volume (LVESV), left ventricular end-diastolic volume (LVEDV), stroke volume (SV), ejection fraction (EF), sphericity index (SI), wall motion score index (WMSI). Figures 2 and 3.

Because mitral annular area reaches maximum in late-diastole and to minimum in mid-systole, the parameters related to mitral annular geometry were measured in late-diastole and mid-systole [9].

IMR was assessed quantitatively by (1) TTE- the proximal isovelocity surface area (PISA) method-RV and effective regurgitant orifice (ERO) were calculated, (Fig. 4) and vena contracta width (VCW), and (2) CMR - by subtracting left ventricle stroke volume and aortic flow on velocity encoded imaging [10].

\section{Statistical analysis}

Statistical analysis was performed using SPSS software (version 11.5). Numerical data are expressed as mean \pm standard deviation. The correlation between
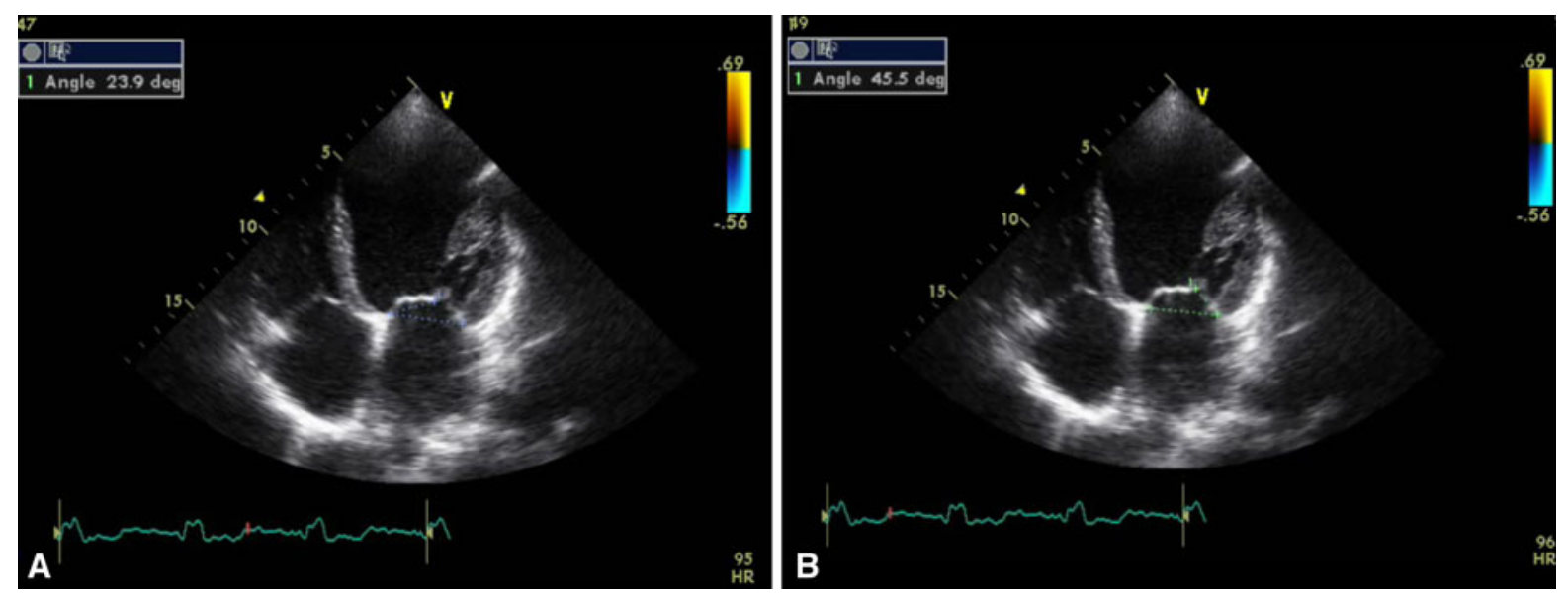

Fig. 1 The measurement of anterior mitral leaflet angle (AMLA)—23.9 degree (a) and posterior mitral leaflet angle (PMLA) — 45.5 degree (b) by echocardiography. Four-chamber view 


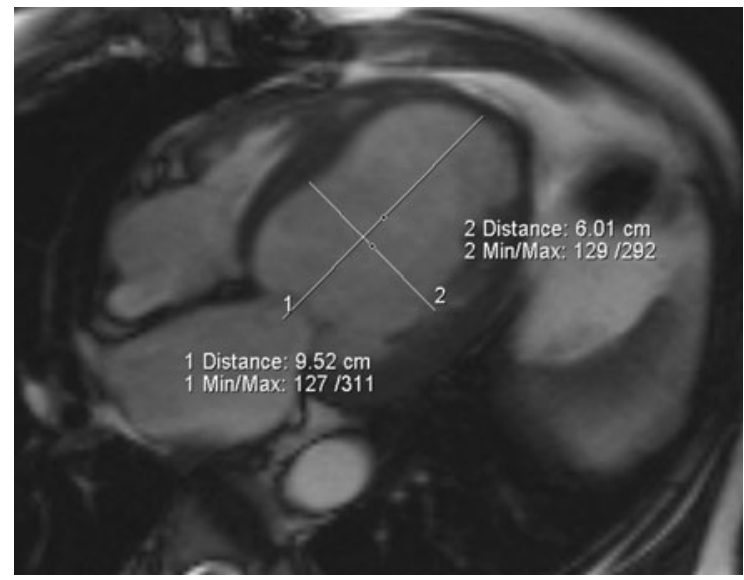

Fig. 2 The measurement of sphericity index (SI) -0.63 by CMR

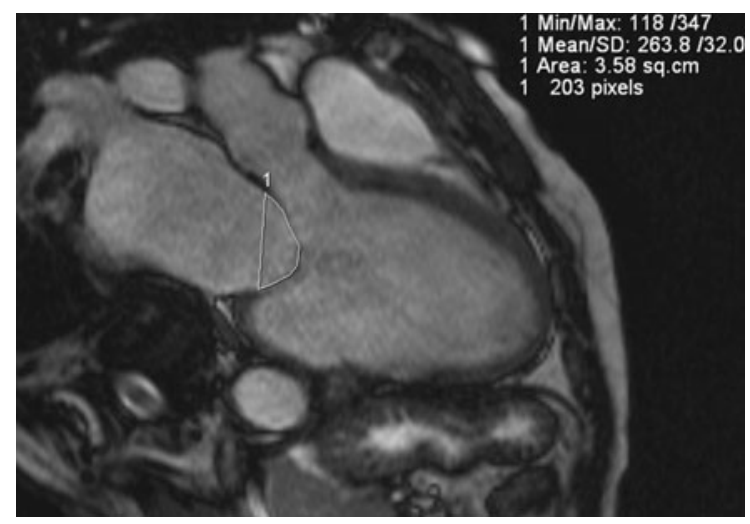

Fig. 3 The measurement of tenting area (TA) $-3.58 \mathrm{~cm}^{2}$ by CMR
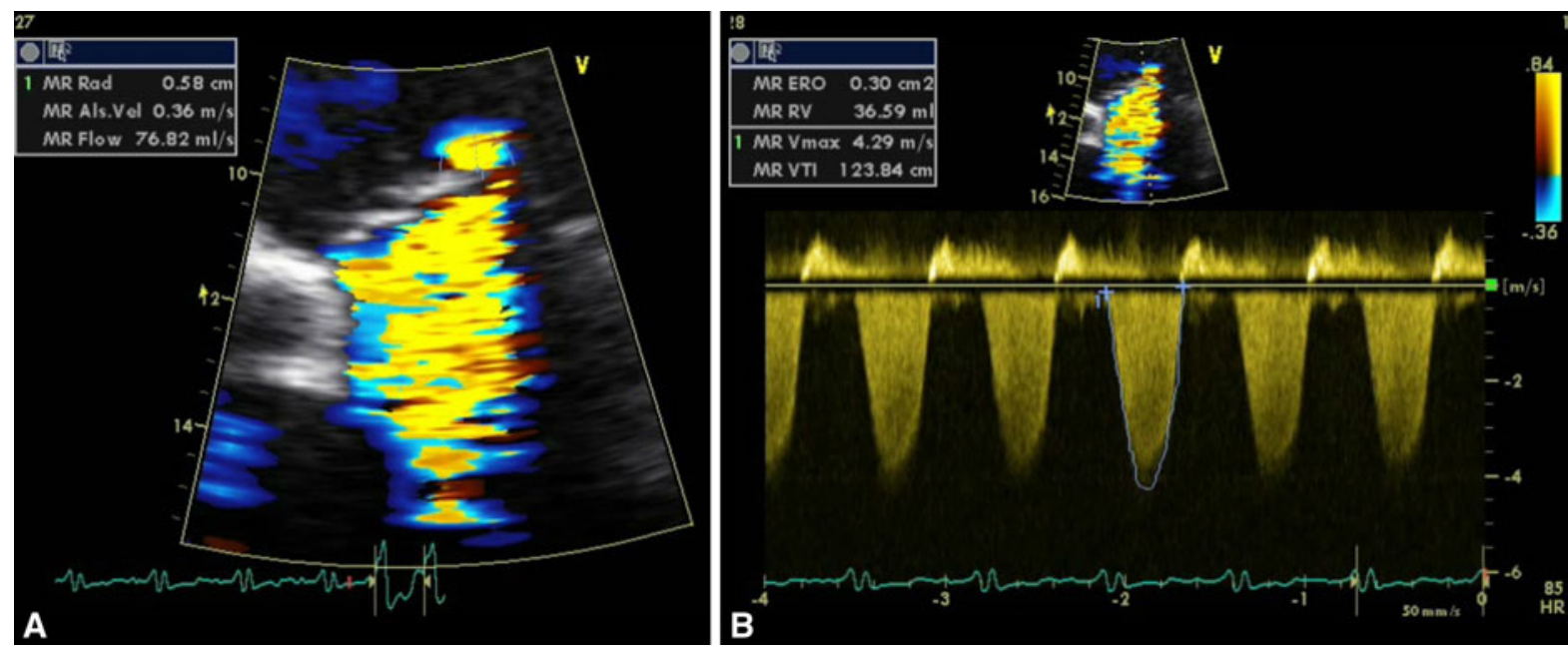

Fig. 4 a, b. Severe mitral regurgitation - the quantitative assessment by echocardiography using PISA (Proximal Isovelocity Surface Area) method. Regurgitant volume (RV)-36.6 ml. Effective regurgitant orifice (ERO) $-0.30 \mathrm{~cm}^{2}$ anterior and posterior mitral leaflet angles and LV remodeling, mitral deformation and severity of IMR parameters was assessed using Pearson's test.

Intraobserver and interobserver variability for measurement of the echocardiographic and CMR parameters was determined for two independent observers, using Cohen's correlation coefficient method. Differences were considered significant at $P<0.05$.

\section{Results}

On TTE the mean value of anterior and posterior mitral leaflet angle was $25.41 \pm 4.28$ and $38.37 \pm$ $8.89^{\circ}$. By CMR the mean values of anterior and posterior mitral leaflet angle were $25.74 \pm 3.09$ and $38.94 \pm 6.32$ degree, respectively.

Five patients $(11.9 \%)$ had posterior mitral leaflet angle exceeding $45^{\circ}$.

There was a strong correlation between echocardiography and CMR for assessing AML $(r=0.77$; $P=0.001$ and PML $(r=0.83 ; P=0.001)$.

The IMR severity parameters were as follows: ERO 0.24 , VCW $0.61 \pm 0.80 \mathrm{~cm}$.Mitral deformation indices including coaptation height $(\mathrm{CH})$ and tenting area (TA) were $1.49 \pm 0.41 \mathrm{~cm}$ and $3.95 \pm 1.64 \mathrm{~cm}^{2}$.

By CMR, the RV was $20.01 \pm 13.48 \mathrm{ml}$ and $\mathrm{RF}$ $0.23 \pm 0.12$. There was a significant correlation between TTE and CMR for assessing RV $(r=0.688$, $0.16 \pm 0.12 \mathrm{~cm}^{2}, \mathrm{RV} 26.37 \pm 14.59 \mathrm{ml}, \mathrm{RF} 0.38 \pm$ 
$P=0.001)$ and RF $(r=0.539, P=0.001)$ and also for $\mathrm{CH}(r=0.606, P<0.001)$ and TA $(r=0.676$, $P<0.001)$.

Mean values of CMR data are presented in Table 2.

For all studied subjects (RV $>20 \mathrm{ml}$ ), there was a good correlation between anterior mitral leaflet angle and RV $(r=0.74, P=0.01)$. This correlation was stronger $(r=0.97, P=0.005)$ in patients with a more severe MR $(\mathrm{RV}>30 \mathrm{ml})$. In addition, in this group of patients, there was a significant correlation between the RV and posterior mitral leaflet angle ( $r=0.90, P=0.037)$, between tenting area and posterior mitral leaflet angle $(r=0.90, P=0.04)$, between tenting area and anterior mitral leaflet angle $(r=0.82, P=0.08)$. There was also a weak but significant correlation between PML angle and MADs ant-post (mitral annulus diameter (anteroposterior) in systole ( $r=0.34, P=0.039)$ (Table 3 ). Besides, there was a correlation between PML angle and $\operatorname{LAV}(r=0.41, P=0.012)$.

Among the parameters of LV remodeling, there was a significant correlation, for all the group of patients, between posterior mitral leaflet angle and LVEDV index $(r=0.35, P=0.031)$, LVESV index $(r=0.37, P=0.021), \mathrm{SV}(r=0.35, P=0.03), \mathrm{SI}$ $(r=0.33, P=0.041)$. AML angle correlated only with WMSI $(r=0.41, P=0.019)$.

Table 2 The CMR parameters expressed as mean $\pm \mathrm{SD}$, minimum and maximum values

\begin{tabular}{|c|c|c|c|}
\hline & Mean \pm SD & Minimum & Maximum \\
\hline Coaptation height (cm) & $1.37 \pm 0.46$ & 0.74 & 2.76 \\
\hline Tenting area $\left(\mathrm{cm}^{2}\right)$ & $3.39 \pm 1.38$ & 1.45 & 6.03 \\
\hline Mitral annular area syst. $\left(\mathrm{cm}^{2}\right)$ & $10.70 \pm 2.94$ & 5.69 & 17.98 \\
\hline Mitral annular area diast. $\left(\mathrm{cm}^{2}\right)$ & $12.28 \pm 2.90$ & 7.45 & 19.66 \\
\hline MADs ant-post (cm) & $3.14 \pm 0.59$ & 1.8 & 4.24 \\
\hline MADs sept-lat (cm) & $3.49 \pm 0.54$ & 2.5 & 4.58 \\
\hline MADs ant-inf (cm) & $3.85 \pm 0.55$ & 2.9 & 5 \\
\hline MADs mean $(\mathrm{cm})$ & $3.49 \pm 0.50$ & 2.4 & 4.41 \\
\hline MADd ant-post (cm) & $3.53 \pm 0.61$ & 2.2 & 4.6 \\
\hline MADd sept-lat (cm) & $3.76 \pm 0.49$ & 2.75 & 4.91 \\
\hline MADd ant-inf (cm) & $4.11 \pm 0.52$ & 3.2 & 5.1 \\
\hline MADd mean $(\mathrm{cm})$ & $3.80 \pm 0.48$ & 2.87 & 4.77 \\
\hline Sphericity index (SI) & $0.56 \pm 0.09$ & 0.38 & 0.77 \\
\hline $\mathrm{RV}(\mathrm{ml})$ & $20.01 \pm 13.48$ & 0.93 & 63.24 \\
\hline $\mathrm{RF}$ & $0.23 \pm 0.12$ & 0.01 & 0.6 \\
\hline LVEDDI & $3.51 \pm 0.57$ & 2.32 & 5.2 \\
\hline LVESDI & $4.53 \pm 9.43$ & 1.61 & 57.73 \\
\hline LVEDVI & $138.76 \pm 50.96$ & 65.68 & 304.34 \\
\hline LVESVI & $91.91 \pm 48.96$ & 21.46 & 243.71 \\
\hline SVI & $46.80 \pm 9.19$ & 33.09 & 65.82 \\
\hline $\mathrm{SV}(\mathrm{ml})$ & $85.76 \pm 18.70$ & 53 & 129 \\
\hline $\mathrm{EF}$ & $36.54 \pm 13.46$ & 19 & 67.3 \\
\hline LAV (ml) & $73.61 \pm 34.22$ & 27.86 & 192.25 \\
\hline WMSI tot & $2.11 \pm 0.50$ & 1.12 & 2.88 \\
\hline
\end{tabular}

EF Ejection fraction, $L A V$ Left atrial volume, $L V E D D I$ Left ventricular end-diastolic diameter index, $L V E D V I$ Left ventricular enddiastolic volume index, LVESDI Left ventricular end-systolic diameter index, LVESVI Left ventricular end-systolic volume index, MADd ant-inf Mitral annular diameter in diastole -d - (infero-anterior), MADd ant-post Mitral annular diameter in diastole -d (antero-posterior), MADd sept-lat Mitral annular diameter in diastole -d - (septo-lateral), MADs ant-inf Mitral annular diameter in systole -s - (infero-anterior), MADs ant-post Mitral annular diameter in systole -s - (antero-posterior), MADs sept-lat Mitral annular diameter in systole -s - (septo-lateral), $R F$ Regurgitant fraction, $R V$ Regurgitant volume, $S V$ Stroke volume, $S V I$ Stroke volume index, WMSI tot Wall motion score index (total) 
Table 3 The correlation between anterior and posterior mitral leaflet angle values and indices of LV remodeling, mitral apparatus deformation and IMR severity

\begin{tabular}{lll}
\hline Analyzed parameters & $\mathrm{P}$ & $r$ \\
\hline AML angle/Regurgitant volume $(\mathrm{RV}>20 \mathrm{ml})$ & 0.01 & 0.74 \\
AML angle/Regurgitant volume $(\mathrm{RV}>30 \mathrm{ml})$ & 0.005 & 0.97 \\
PML angle/Regurgitant volume $(\mathrm{RV}>30 \mathrm{ml})$ & 0.037 & 0.90 \\
PML angle/Tenting area $(\mathrm{RV}>30 \mathrm{ml})$ & 0.04 & 0.90 \\
AML angle/Tenting area $(\mathrm{RV}>30 \mathrm{ml})$ & 0.08 & 0.82 \\
PML angle/MADs ant-post & 0.039 & 0.34 \\
PML angle/LVEDVI & 0.031 & 0.35 \\
PML angle/LVESVI & 0.021 & 0.37 \\
PML angle/SV & 0.03 & 0.35 \\
AML angle/WMSI tot & 0.019 & 0.41 \\
PML angle/SI & 0.041 & 0.33 \\
PML angle/LAV & 0.012 & 0.41 \\
\hline AML Anteior mital &
\end{tabular}

$A M L$ Anterior mitral leaflet, IMR Ischemic mitral regurgitation, $L A V$ Left atrial volume, $L V E D V I$ Left ventricular end-diastolic volume index, LVESVI Left ventricular end-systolic volume index, MADs ant-post Mitral annular diameter in systole -s (antero-posterior), $P M L$ Posterior mitral leaflet, $R V$ Regurgitant volume, SI Sphericity index, SV Stroke volume, WMSI tot Wall motion score index (total)

Inter-observer and intra-observer variability tested by the Cohen's method showed a concordance of 94 and $95 \%$ for echocardiographic and 95 and $96 \%$ for CMR parameters.

\section{Comment}

We have found that, in patients with chronic ischaemic mitral regurgitation (IMR), the value of anterior and posterior mitral leaflet angle determined by echocardiography correlates with the parameters of mitral apparatus deformation and LV remodeling indices by TTE and CMR. We found that echocardiographic measurement of tenting area, coaptation height and the mitral leaflet angles are highly concordant with the CMR measurements. This is important as echocardiography remains the primary diagnostic tool in patients with IMR and the therapeutic decisions (including referral for surgery and the choice between repair vs. replacement) are usually made on the basis of a thourough echocardiogram while IMR remains a diagnostic and therapeutic challenge.

In particular, it is still not clear what patients and when (i.e., at what stage of IMR and on the basis of what particular parameters) should be referred for surgery [11]. In the past, the decision was based on parameters such as the mitral regurgitant jet extent (colour Doppler), the colour flow jet area, jet length and width, the ratio of the jet area to the left atrial area, the intensity of the continuous wave Doppler signal, the pulmonary venous flow contour or the peak early mitral inflow velocity. Those parameters, however, have been shown to be insufficient in assessing the severity of IMR in the context of the need for surgery. More recently, the quantitative IMR assessment (effective regurgitant orifice, ERO, regurgitant volume, RV, and the vena contracta width, VCW) has been indicated as the method of choice for grading the severity of IMR [12-14]. Indeed, PISA and VCW show a much better correlation with angiographic grading of MR than the semi-quantitative methods [14-16]. An effective regurgitant orifice $>0.2 \mathrm{~cm}^{2}$ and regurgitant volume $>30 \mathrm{ml}$ are associated with a poor long-term prognosis and thus those values indicate a severe IMR $[17,18]$.

There is a great interest in identifying new parameters of IMR severity. Kwan and colleagues [19] indicated the posterior leaflet angle of $>47^{\circ}$ as the cut-off value discriminating between significant ( $\geq$ moderate) and non-significant IMR (sensitivity of $96 \%$ and specificity of $84 \%$ ). Magne and co-workers [3] suggested that posterior leaflet angle $\geq 45^{\circ}$ was related to a poor 3 -years outcome in patients after mitral valve repair due to IMR. However, not only severe but also mild IMR is associated with an adverse prognosis due to the an additional hemodynamic load on the post-infarcted ventricle [20].

The indications for mitral valve surgery in chronic IMR are not well defined. In most cases, in patients with severe IMR coronary bypass grafting alone is not sufficient to cure or even to reduce its degree [21]. It is generally agreed that patients who have indications for coronary artery bypass grafting (CABG) with moderate-to-severe IMR (3 or 4 grade) should also undergo concomitant MV surgery [22-24]. However, it is controversial whether concomitant MV surgery should be performed in CABG patients with mild-to-moderate IMR (1 or 2 grade) [22]. Malidi and co-workers [25] compared, in patients treated by isolated CABG, the outcome between those with mild-to-moderate IMR versus those without IMR. They found a higher prevalence of heart failure symptoms and decreased cardiac event-free survival in IMR patients. In 
addition, $30 \%$ of patients progressed to 3 or 4 grade MR during a mean follow-up of 16 months. Those findings would suggest that MV surgery should be considered at the time of CABG even in patients with mild-to-moderate IMR, but the parameters on which the decision should be made remain to be definedparticularly since in moderate IMR the clinical utility of mitral valve repair remains unproven [11, 26, 27]. In particular, the risk of long-term MR and heart failure progression must be balanced against the increased perioperative risk of the additional MV procedure [25]. Borg and coworkers [22] recommend that patients with mild-to-moderate IMR and multiple comorbidities, or a life expectancy of less than 5 years, should undergo CABG only.

The most common surgical procedure currently performed for chronic IMR is restrictive mitral annuloplasty [28, 29]. However, mitral valve replacement remains a reasonable surgical option in subgroups of patients with IMR, predominantly because of its reliability and reproducibility. Mitral valve replacement should be considered for patients with chronic IMR and multiple comorbidities, complex regurgitant jets (non-central jet or several jets), or severe tethering of both MV leaflets [29, 30]. Calafiore and coworkers [29] recommend MV replacement when the distance between the coaptation point of the leaflets and the plane of the mitral annulus (coaptation height) exceeds $1.0 \mathrm{~cm}$.

Recurrent IMR despite surgical annuloplasty is related to leaflet tethering by progressive left ventricular remodeling [30-33]. Among the pre-operative echocardiographic parameters, obtained by transthoracic approach, the most important in predicting persistent or recurrent MR after annuloplasty are tenting area $2.5 \mathrm{~cm}^{2}$, coaptation height $1.0 \mathrm{~cm}$, central jet of MR, complex regurgitant jets, restrictive diastolic filling profile, severe enlargement of the left ventricle and posterior mitral leaflet angle value $\geq 45^{\circ}$ $[21,34]$. In a study of 51 patients subjected to mitral valve repair, those with posterior mitral leaflet angle value $\geq 45^{\circ}$ had significantly lower 3-year event-free survival ( $22 \pm 17 \%$ vs. $76 \pm 12 \%, P<0.001)$ [3].

We showed that the posterior mitral leaflet angle value highly correlated with regurgitant volume and tenting area ( $r=0.90, r=0.90$, respectively). However, our findings also suggest that it may be important to evaluate the anterior mitral leaflet angle, especially in the group of patients with a more severe MR
$(\mathrm{RV}>30 \mathrm{ml})$. In those patients, we found a strong correlation between the anterior mitral leaflet angle and regurgitant volume or tenting area $(r=0.97$, $r=0.82$ respectively). Thus our current findings and those of Magne and colleagues [3] indicate that the consideration of the anterior leaflet angle in combination with the other indices of mitral valve morphology may be useful to guide the operative strategy. In our study group, the five patients $(11.9 \%)$ with the posterior mitral leaflet angle value $>45^{\circ}$ were referred to mitral valve replacement with chordal sparing.

\section{Limitations}

The present study was based on 2D echocardiography while $3 \mathrm{D}$ echo can provide more precise geometric information on the mitral apparatus deformation and left ventricular remodeling. However, in a majority of cardiovascular centers today, the $2 \mathrm{D}$ echo remains the most common imaging modality in patients with IMR. Importantly, our measurements of mitral leaflet angles by $2 \mathrm{D}$ echo were correlated not only with the echocardiographic but also CMR parameters of mitral apparatus deformation and LV remodeling.

In our study, the assessment of IMR was done at rest. Recent work by Lancellotti and colleagues [35] shows that chronic IMR is dynamic during exercise, and that an increase in ERO $\geq 13 \mathrm{~mm}^{2}$ on exercise can identify the subgroup of patients at a higher risk of cardiac events. Thus it is likely that evaluation of IMR on exercise will need to be considered in the decisionmaking algorithms in patients with chronic IMR.

\section{Conclusion}

In patients with ischemic mitral regurgitation, we have shown that the values of both the anterior and posterior mitral leaflet angle determined by echocardiography correlate with the severity of IMR, mitral apparatus deformation and LV remodeling indices by CMR. This indicates that measurement of anterior and posterior mitral leaflet angles may play an important role in evaluating patients with IMR.

A further large, multi-center study will determine the usefulness of anterior and posterior mitral leaflet angles as parameters in decision-making in this challenging group of patients. 
Conflict of Interest The authors declare that they have no competing interests.

Open Access This article is distributed under the terms of the Creative Commons Attribution Noncommercial License which permits any noncommercial use, distribution, and reproduction in any medium, provided the original author(s) and source are credited.

\section{References}

1. Iung B (2003) Management of ischaemic mitral regurgitation. Heart 89:459-464

2. Kumanohoso T, Otsuji Y, Yoshifuku S et al (2003) Mechanism of higher incidence of ischemic mitral regurgitation in patients with inferior myocardial infarction: quantitative analysis of left ventricular and mitral valve geometry in 103 patients with prior myocardial infarction. J Thorac Cardiovasc Surg 125:135-143

3. Magne J, Pibarot P, Dagenais F, Hachicha Z, Dumesnil JG, Sénéchal M (2007) Preoperative posterior leaflet angle accurately predicts outcome after restrictive mitral valve annuloplasty for ischemic mitral regurgitation. Circulation 115:782-791

4. Hendel RC, Budoff MJ, Cardella JF, Chambers CE, Dent JM, Fitzgerald DM, Hodgson J McB, Klodas E, Kramer CM, Stillman AE, Tilkemeier PL, PR Ward, Weigold Wm G, White RD, Woodard PK (2009) ACC/AHA/ACR/ASE/ ASNC/HRS/NASCI/RSNA/SAIP/SCAI/SCCT/SCMR/SIR 2008 Key Data Elements and Definitions for Cardiac Imaging: A Report of the American College of Cardiology/ American Heart Association Task Force on Clinical Data Standards (Writing Committee to Develop Clinical Data Standards for Cardiac Imaging). Circulation 119:154-186

5. Zoghbi WA, Enriquez-Sarano M, Foster E et al (2003) Guidelines. American Society of echocardiography: recommendations for evaluation of the severity of native valvular regurgitation with two-dimensional and Doppler echocardiography. Eur J Echocardiography 4:237-261

6. Kon MW, Myerson SG, Moat NE, Pennell DJ (2004) Quantification of regurgitant fraction in mitral regurgitation by cardiovascular magnetic resonance: comparison of techniques. J Heart Valve Dis 13(4):600-607

7. Hundley WG, Bluemke D, Bogaert JG, Friedrich MG, Higgins CB, Lawson MA et al (2009) Society for cardiovascular magnetic resonance guidelines for reporting cardiovascular magnetic resonance examinations. J Cardiovasc Magn Reson 11:5 (3 March 2009)

8. Lloyd SG, Buckberg GD, the RESTORE Group (2006) Use of cardiac magnetic resonance imaging in surgical ventricular restoration. Eur J Cardio-thoracic Surg 29S: S216-S224

9. Ormiston JA, Shah PM, Tei C, Wong M (1981) Size and motion of the mitral valve annulus in man. A two-dimensional echocardiographic method and findings in normal subjects. Circulation 64:113-120
10. Chan KMJ, Wage R, Symmonds K, Rahman-Haley S, Firmin RH, Pepper J, Pennell DJ, Kilner PJ (2008) Towards comprehensive assessment of mitral regurgitation using cardiovascular magnetic resonance. J Cardiovasc Magn Reson 10:61

11. Lancellotti P, Donal E, Cosyns B, Van Camp G, Monin JL, Brochet E, Berrebi A et al (2008) Effects of surgery on ischaemic mitral regurgitation: a prospective multicente registry (SIMRAM registry). Eur J Echocardiogr 9:26-30

12. Enriquez-Sarano M, Tribouilloy C (2002) Quantitation of mitral regurgitation: rationale, approach, and interpretation in clinical practice. Heart 88(Suppl IV):iv1-iv4

13. Grossmann G, Hoffmeister A, Imhof A, Giesler M, Hombach V, Spiess J (2003) Reproducibility of the proximal flow convergence method in mitral and tricuspid regurgitation. Am Heart J 47:721-728

14. Dujardin KS, Enriquez-Sarano M, Bailey KR, Nishimura RA, Seward JB, Tajik AJ (1997) Grading of mitral regurgitation by quantitative Doppler echocardiography: calibration by left ventricular angiography in routine clinical practice. Circulation 96:3409-3415

15. Leśniak-Sobelga A, Olszowska M, Kostkiewicz M, Podolec P, Tracz W (2002) Quantitative assessment of mitral regurgitation: comparison of echo- cardiographic and angiographic methods. Acta Cardiol 57:55-56

16. Leśniak-Sobelga A, Olszowska M, Pieniążek P et al (2004) Vena contracta width as a simple method of assessing mitral valve regurgitation. Comparison with Doppler quantitative methods. J Heart Valve Dis 13:608-614

17. Grigioni F, Enriquez-Sarano M, Zehr KJ, Bailey KR, Tajik AJ (2001) Ischemic mitral regurgitation: long-term outcome and prognostic implications with quantitative Doppler assessment. Circulation 103:1759-1764

18. Enriquez-Sarano M, Avierinos JF, Messika-Zeitoun D, Detaint D, Capps M, Nkomo V, Scott C, Schaff HV, Tajik AJ (2005) Quantitative determinants of the outcome of asymptomatic mitral regurgitation. New Engl J Med 352:875-883

19. Kwan J, Gillinov MA, Thomas JD, Shiota T (2007) Geometric predictor of significant mitral regurgitation in patients with severe ischemic cardiomyopathy, undergoing Dor procedure: a real-time 3D echocardiographic study. Eur J Echocardiogr 8:195-203

20. Agricola E, Oppizzi M, Pisani M, Meris A, Maisano F, Margonato A (2008) Ischemic mitral regurgitation: mechanisms and echocardiographic classification. Eur J Echocardiogr 9:207-221

21. Lancellotti P, Marvick T, Pierard LA (2008) How to manage ischaemic mitral regurgitation. Heart 94:1497-1502

22. Borger MA, Alam A, Murphy PM, Doenst T, David TE (2006) Chronic ischemic mitral regurgitation: repair, replace or rethink? Ann Thorac Surg 81:1153-1161

23. Condado JA, Vélez-Gimón M (2003) Catheter-based approach to mitral regurgitation. J Intervent Cardiol 16: 523-534

24. Canadian Cardiovascular Consensus 2004 (2004) surgical management of Valvular heart disease. Can J Cardiol 20:33E-49E

25. Mallidi HR, Pelletier MP, Lamb J et al (2004) Late outcomes in patients with uncorrected mild to moderate mitral 
regurgitation at the time of isolated coronary artery bypass grafting. J Thorac Cardiovasc Surg 127:636-644

26. Grossi EA, Goldberg JD, La Pietra A et al (2001) Ischemic mitral valve reconstruction and replacement: comparison of long-term survival and complications. J Thorac Cardiovasc Surg 122:1107-1124

27. Di Mauro M, Di Giammarco G, Vitolla G, Contini M, Iaco AL, Bivona A et al (2006) Impact of no-to-moderate mitral regurgitation on late results after isolated coronary artery bypass grafting in patients with ischemic cardiomyopathy. Ann Thorac Surg 81:2128-2134

28. Al-Radi OO, Austin PC, Tu JV, David TE, Yau TM (2005) Mitral repair versus replacement for ischemic mitral regurgitation. Ann Thorac Surg 79:1260-1267

29. Calafiore AM, Di Mauro M, Gallina S et al (2004) Mitral valve surgery for chronic ischemic mitral regurgitation. Ann Thorac Surg 77:1989-1997

30. Gillinov AM, Wierup PN, Blackstone EH et al (2001) Is repair preferable for ischemic mitral regurgitation? J Thorac Cardiovasc Surg 122:1125-1141

31. Hung J, Guerroro JL, Handschumacher BS, Supple G, Sullivan S, Levine RA (2002) Reverse ventricular remodeling reduces ischemic mitral regurgitation: echo-guided device application in the beating heart. Circulation 106:2594-2600

32. Hung J, Papakostas L, Tahta SA et al (2004) Mechanism of recurrent ischemic mitral regurgitation after annuloplasty: continued LV remodeling as a moving target. Circulation 110(Suppl 2):85-90

33. McGee EC Jr, Gillinov AM, Blackstone EH, Rajeswaran J, Cohen G, Najam F, Shiota T, Sabik JF, Lytle BW, McCarthy PM, Cosgrove DM (2004) Recurrent mitral regurgitation after annuloplasty for functional ischemic mitral regurgitation. J Thorac Cardiovasc Surg 128:916-924

34. Kongsaeropong V, Shiota M, Gillinov AM et al (2006) Echocardiographic predictors of successful versus unsuccessful mitral valve repair in ischemic mitral regurgitation. Am J Cardiol 98:504-508

35. Lancellotti P, Troisfontaines P, Toussaint A-C, Luc A, Pierard LA (2003) Prognostic importance of exerciseinduced changes in mitral regurgitation in patients with chronic ischemic left ventricular dysfunction. Circulation 108:1713-1717 